\title{
Behind the Scenes of the 2014 MeCCSA PGN Conference
}

\author{
TOUSSAINT NOTHIAS and CHRISTIAAN DE BEUKELAER \\ University of Leeds
}

\begin{abstract}
This article provides insights about the organization of the 2014 MeCCSA PGN conference that forms the basis for the publication of this special issue of Networking Knowledge. In this piece, the two organizers reflect on the organization and theme of the conference to contextualize the special issue through a report that blends a personal narrative with a visual essay.
\end{abstract}

\section{KEYWORDS}

MeCCSA PGN; Conference Organization.

Like any serious academic initiative, the organization of the MeCCSA PGN Conference at Leeds started with some music and a drink. In that case, it was the song 'Independence Cha Cha' by Belgio-Congolese rapper Baloji and a glass of Rioja; or a bottle, to be honest. When Ruth Sanz Sabido sent out the first call to organize the conference on the MeCCSA diffusion list in December 2012, we were sitting across each other in the living room of our shared flat. We had one of these evenings that generally happen when $\mathrm{PhD}$ students live together: mixing a casual and friendly conversation with the sporadic yet constant checking of emails. Incoming emails punctuated, integrated in or slowed down our conversation. It depended on the degree of interest we show in them, and whether we decided to delete them, forward them to colleagues who might be interested, discuss them on the spot or just "keep them for later as something-interesting-that-I-hope-I'll-be-able-to-engage-with-at-some-point".

When the call to organize the postgraduate conference appeared, we were both in front of our laptops. There was a silence. Then, one asked "Did you see the..." only to be interrupted by the other "The MeCCSA conference? Yes." There was another silence as we both dug back into the call. "You know, the conference has never been held in Leeds before." "Our new building is a perfect venue for a conference this size." "Leeds is well located within the UK rail system." "Staff in the department could convene the panel sessions." "It would be great to get involved in the MeCCSA PG network." "It would be so much fun." "Come on, let's do this!" Or, to quote Ron Burgundy: "Well, that escalated quickly". One of us poured some more wine as the other prepared the flipchart to start brainstorming ideas for our proposal. 
We decided to give this year's conference a theme: "Global Interdependence: Knowledge, Experience, Theory". We settled on this theme, partly because it connected to our respective research, but also because it provided an interesting way to frame the conference of a national association. This theme was at once broad enough to be inclusive and specific enough for the conference to be experienced holistically as a themed event. It invited participants to actively seek out links between panels, papers and researchers, to look beyond narrow and specific research interests to embrace the interdisciplinarity that makes up MeCCSA's identity.

On the opening day of the conference, we didn't talk of the theme as merely a theme, but more as a "vibe". A conference is, in many ways, like a jam session. The 'standards' of Jazz are much like the theories of social science: we all recognize them, but play them in a slightly different way. And the timbre, tempo, key, and sound we use to share this melody (or theory) make all the difference. The important thing is that we have taken a theory or idea out into the world, and made it our own; and through the clash it makes with our ideas and observations, this theory transforms. When presenting it, our data become the basis for variation (and at times improvisation) on the theme. And, in the best of cases, we find further inspiration in jamming with fellow researchers. We share ideas in a supportive manner. We find a common thread throughout the session that allows us to both play together and have solos. We look for exciting dissonance that stretches the imagination and understanding of the 'standard' that we play and present. At times, a seasoned special guest makes her or his appearance, to give a solo that resonates with the previous songs, or set the stage for the next ones. It is in this way that we decided to introduce the conference theme as a "vibe": the somehow immaterial, shared, pleasurable atmosphere that links participants to each other in an auratic here and now.

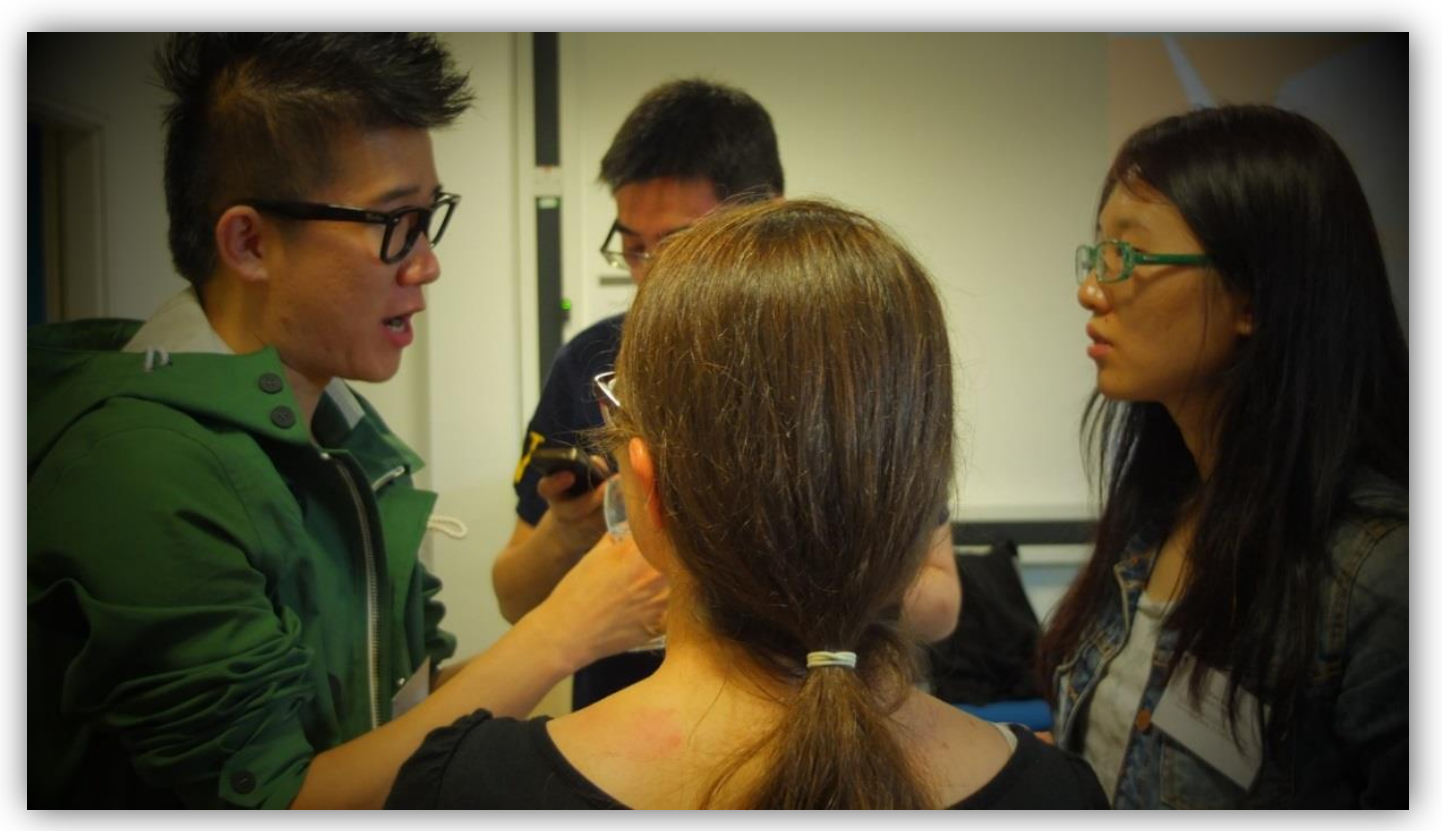

Post-graduate Network(ing) Tianyang 'Oscar' Zhou (left) and Xiao ‘Adelaide' Wong (right). 


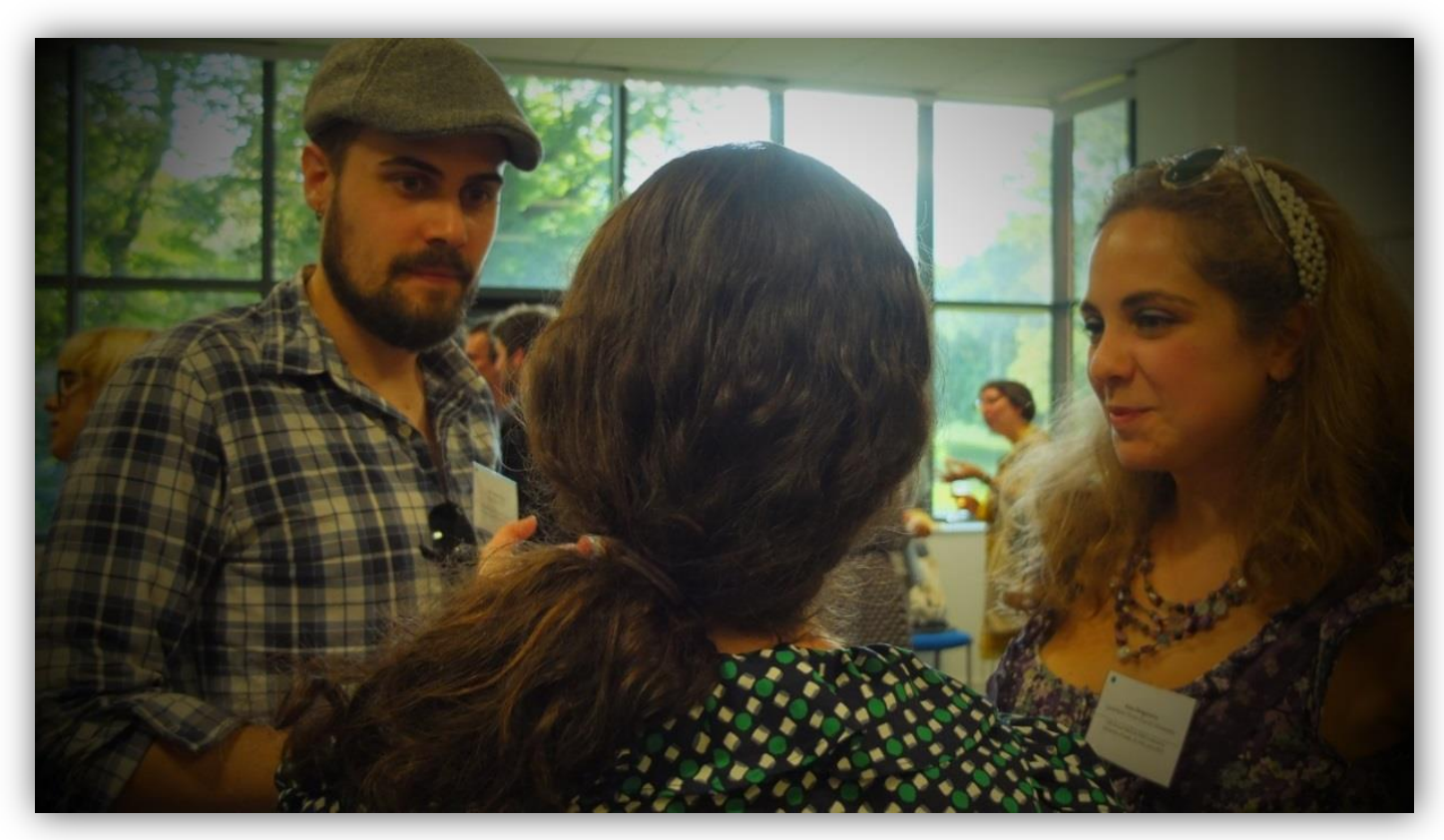

Post-graduate Network(ing), Christophe Magis (left) and Asya Draganova (right).

The Global Interdependence of our academic travels and timetable cross path in South Africa in October 2013. We are staying in an AirBnB in the Central Business District of Johannesburg, where we decide to spend an afternoon discussing who we would and could invite. With a two-day conference in mind, we settled on having four keynotes to punctuate the beginning and end of each day. We insisted on having a clear balance in terms of gender and age, but also of provenance: two internal, two external; two relatively early career researchers, one woman and one man; two more senior researchers, one woman and one man.

But, the most important criterion was that the keynotes' research engages with the theme of the conference in a clear, engaged, and different ways. Dr Katy Parry, from the University of Leeds, kicked off the conference with a talk on Pussy Riot and the embodiment of dissent in public spaces from the perspective of globally-aware visual protest. Professor Lilie Chouliaraki, from the London School of Economics, talked about the rise of a self-oriented solidarity and its moral and political implications for public ethics and global activism. Dr Anamik Saha, from Goldsmiths, called upon the work of Stuart Hall to discuss the need to reinvigorate the study of race and ethnicity within media studies today through, notably, the inclusion of more global contexts, a greater engagement with production (and not only representation), and an explicit grounding of discussions of cultural identity within issues of inequality and discrimination. Finally, Professor David Hesmondhalgh from the University of Leeds and author of The Cultural Industries and the recent Why Music Matters, closed the conference by outlining a moral economy of culture approach as a way to bring ethical questions regarding the relations between culture and economy. 


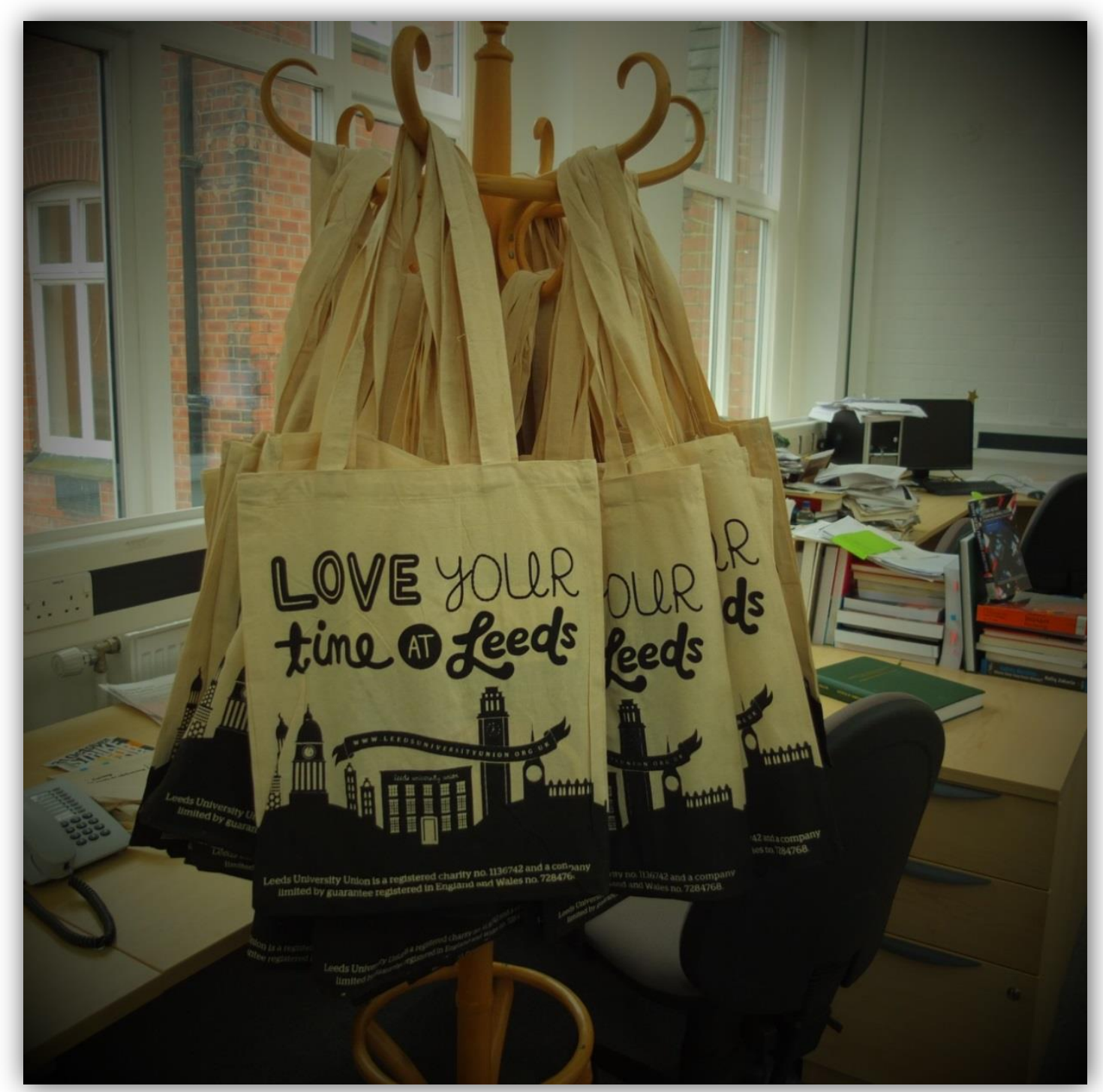

The 'Love Your Time at Leeds' tote bags from Leeds University Union served as conference bags.

The organization of the conference also benefited from local interdependence within the department. We received more than 60 abstracts to review, and were able to count on four of our wonderful colleagues to help review them (Caitlin Schindler, Stuart Shaw, Andreas Rauh Ortega and Jennifer Carlberg). Overall, six different people have read each abstract.

The diversity of research topics and approaches among the abstract submissions is enthralling; and so is the geographical spread of the presenters. In the end, 40 students based in Universities in Turkey, the Netherlands, the UK, Germany, France, Nigeria, India, Belgium, Hungary and Brazil presented their work. Once we received confirmation of participation, we started arranging the paper into panels. Our initial plan was to arrange topical panels covering the variety of topics in MeCCSA and the subjects covered by the research group at Leeds. Leeds staff members would convene panel in their area of expertise. But as we went through the abstract over and over again, we adopted more of a bottom-up approach. Each combination of papers forced us to imagine how presenters would academically dialogue, or jam either way based 
on a common theme, approach, theoretical focus, or geographical link. The end result is a mixture of this bottom-up approach and the initial structure, with general topical panels on, for instance, "Journalism", "Critical Theories", "Political Communication" and "Cultural Industries" and more specific topical panels on "Post-Humanitarianism and the Mediation of Poverty and Distant Suffering", "Music Industries and Identities", and "Creating and Questioning Cultural Value".

All panels had two things in common. First, each panel was convened by a member of the department. Overall, 12 members of staff volunteered their time and provided their expertise. In fact, we received more offer to help than we could accommodate. It was very inspiring to see such a level of engagement and support from senior colleagues. They provided a crucial connective tissue for the conference, by offering responses to papers and bringing them in dialogue. Second, each panel brought in dialogues different geographical areas, thus creating a running opportunity to reflect on the conference theme. In the journalism panel for instance, the four presenters talked about newsrooms practices in Turkey, Pakistan, China and Nigeria. For its part, the music industries and identities panel engaged with Bulgaria, Mauritius and Réunion and India, while the cultural industries panel covered the UK, Nigeria, France, Belgium and Canada.

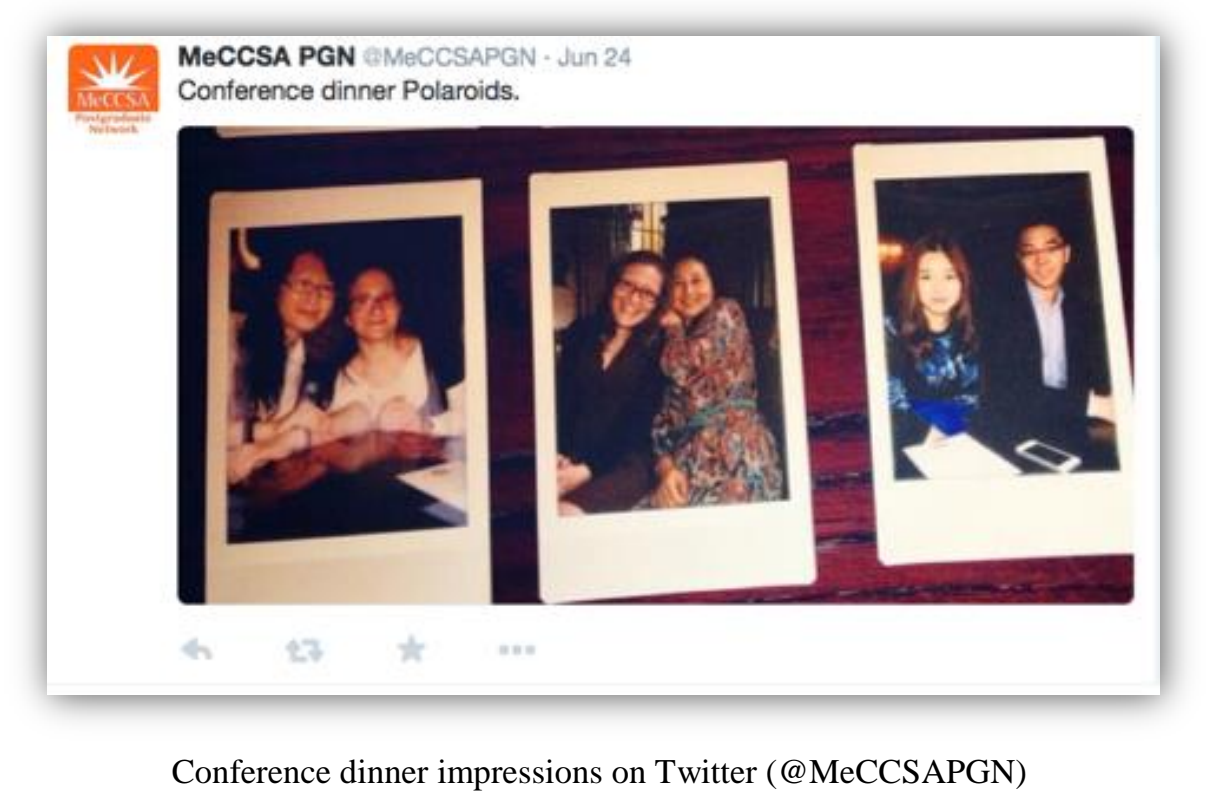

We built on the local inspiration to think of the MeCCSA PGN conference as more than a series of paper presentations through engaging with what the previous MeCCSA PGN conferences had done. They notably inspired us to organize workshops on several professional skills useful to early career researcher at different stage of their PhD. Professor John Corner, editor of Media, Culture and Society, convened a workshop academic publishing. The head of ICS, Dr Bethany Klein and Professor Kate Oakley lead a workshop on the do's and don't of academic CVs and job applications. Finally, two postgraduate researchers, Rachel Tavernor from the University of Sussex and Sam Ward from the University of Notthingham, convened a session on teaching media and cultural studies. 


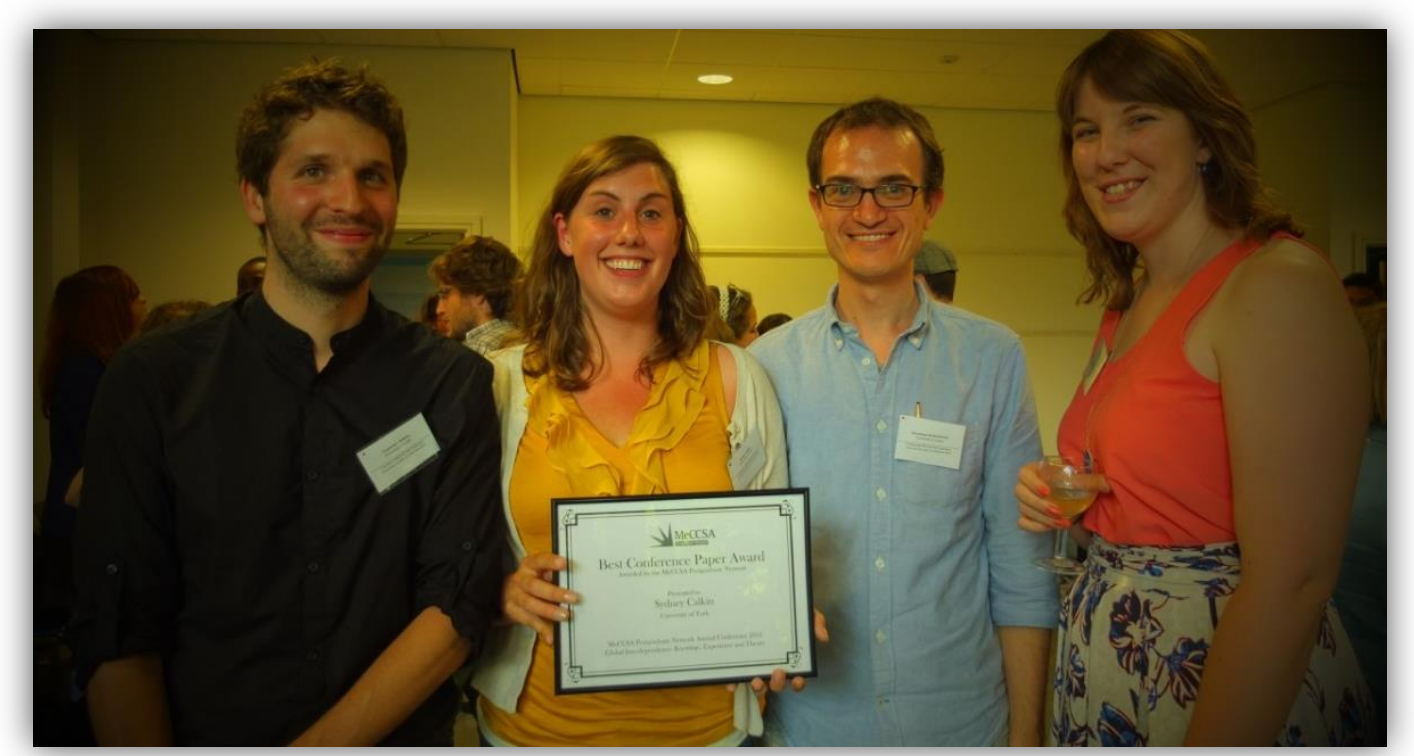

From left to right, Toussaint Nothias, Sydney Calkin, Christiaan De Beukelaer and Rachel Tavernor at the best paper award ceremony.

Openness is also a core feature of the MeCCSA PGN. This was echoed in the choice of providing financial support to two students who wouldn't have been able to come otherwise. For the first time the MeCCSA PGN conference had a best paper award won by Sydney Calkin from the University of York (who since graduated; congratulations, Dr. Calkin!) - which also provided a way to recognize some exceptional work being undertaken by PG researchers. Finally, we also borrowed from the previous conferences - and our personal experiences - the fact that conviviality is key to a successful conference. There was a strong social dimension, with two informal dinners, a pub-quiz dinner on the concluding day, and a day-out in the scenic Yorkshire Dales the day following the conference.

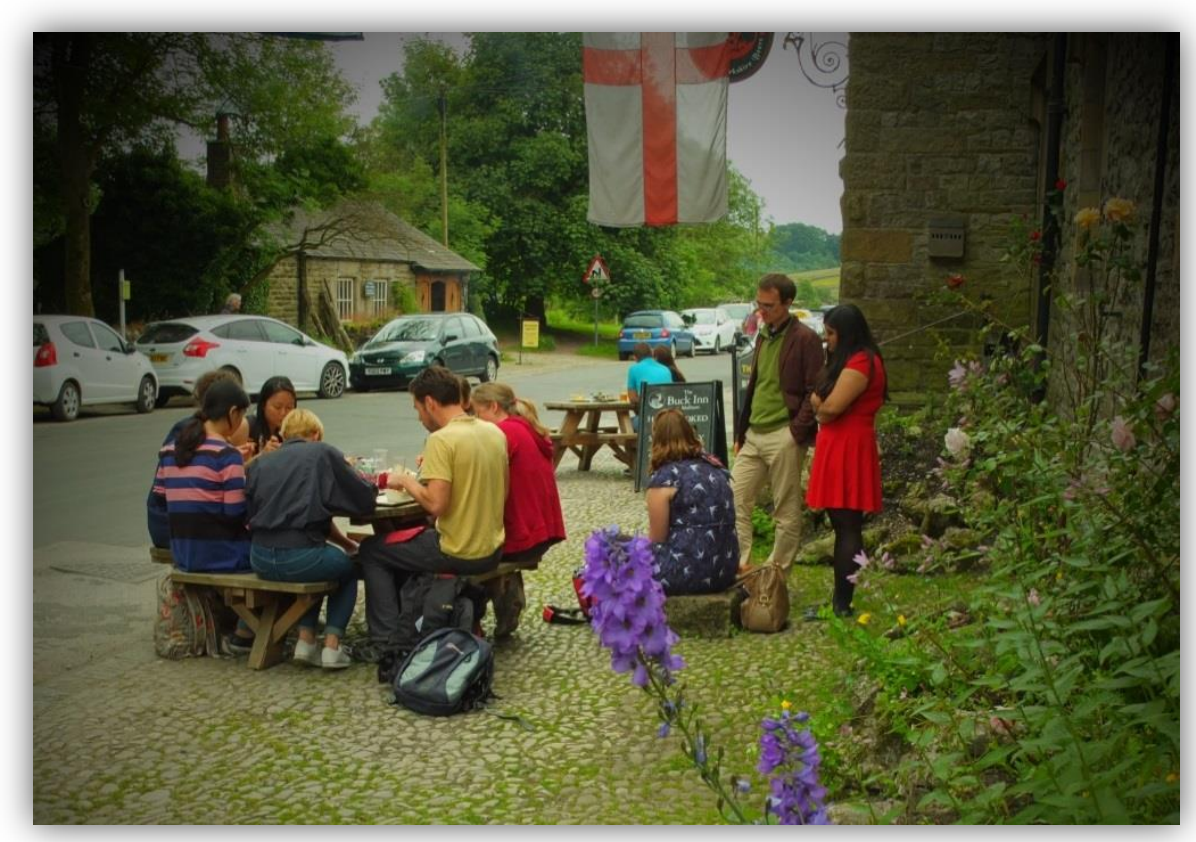

Breaking bread at the Yorkshire Dales, after a walk near Malham. 
The lasting result of the conference - beyond many links between participants - is assuredly the publication of this special issue of Networking Knowledge. It follows a tradition of publishing dedicated issues featuring MeCCSA PGN conferences, and was encouraged by Samuel Ward, the previous editor of the journal. Simon Dawes and Andreas Rauh Ortega cheerfully and professionally took on the task of compiling this special issue. It is a real pleasure for us to know that the conference now lives on beyond those two days in June 2014. In many ways, the genesis of this special issue mirrors the ethos and vibe of the conference. From the Leeds staff who convened panels and workshops to MeCCSA PGN representatives who actively helped and supported the conference (thank you, Rachel Tavernor!); from fellow PhD students at Leeds who reviewed the abstracts and helped on the day, to participants who came from 13 different countries: this conference has been a truly collaborative effort.

If we can think of the conference as a jam session, this special issue as a lasting result counts as the $\mathrm{CD}$ that captured these jams. Enjoy listening! 